\title{
Does acoustic testing strand whales?
}

$\mathrm{M}$ ass strandings of live whales have been explained by proposing many 'natural' or human-related causes'. I found that a recent stranding of Cuvier's beaked whale coincided closely in time and location with military tests of an acoustic system for submarine detection being carried out by the North Atlantic Treaty Organization (NATO).

Cuvier's beaked whale (Ziphius cavirostris) seems to be abundant in the East Ionian Sea (Mediterranean Sea), as indicated by strandings and sightings recorded there from 1992 to 1997. This species is a deep-diving, pelagic cetacean that rarely mass-strands ${ }^{2}$. Only seven strandings of more than four individuals have been recorded since 1963 worldwide, the individuals on these occasions numbering 5, 6, 6, 10, 12, 15 and 19 (refs 3-7). In the Kyparissiakos Gulf specifically, the average number of individual whales stranded every halfyear is 0.7 (s.d. $=0.9, n=11$ ), with the exception of a mass stranding that occurred on 12-13 May 1996 (Fig. 1).

From the morning of 12 May until the afternoon of 13 May, we recorded 12 Cuvier's beaked whales stranded alive along the coasts of the Kyparissiakos Gulf. The whales were spread along 38.2 kilometres of coast and were separated by a mean distance of $3.5 \mathrm{~km}$ (s.d. $=2.8, n=11$ ). This spread in time and location was atypical, as whales usually mass-strand at the same place and at the same time. Two weeks later, one more animal was found decomposing on a remote beach of the neighbouring Zakynthos Island, $57 \mathrm{~km}$ away from the closest stranding on the mainland.

Necropsies of eight stranded animals were carried out, but no apparent abnormalities or wounds were found. Many of the stomach contents that were collected contained cephalopod flesh, indicating that recent feeding had taken place.

After looking for possible causes of the mass stranding, we discovered that 'sounddetecting system trials' had been performed

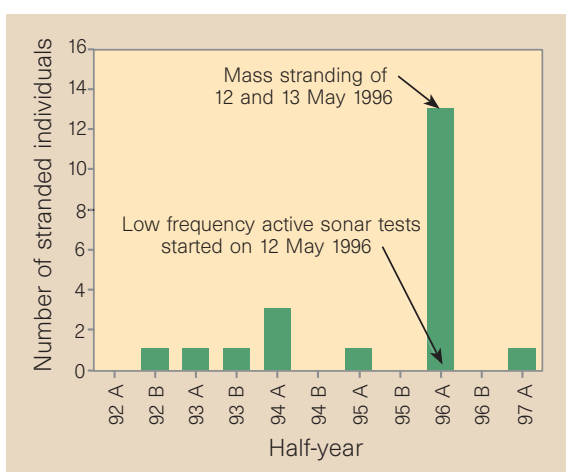

Figure 1 Cuvier's beaked whale strandings in the Kyparissiakos Gulf, 1992-97.

by the NATO research vessel Alliance from 24:00 11 May to 24:00 15 May (Warning to mariners 586 of 1996, Hellenic Navy Hydrographic Service) - a period that encompassed the mass stranding. Also, the officially declared area where the sea trials had been carried out enclosed all the coordinates of the stranding points.

The tests that RV Alliance performed were for Low Frequency Active Sonar (LFAS), a system for the detection of quiet diesel and nuclear submarines. This system generates extremely loud low-frequency sound (maximum output of $\geqslant 230$ decibels as 1 micropascal broadband waveforms centred at frequencies that range from 250 to 3,000 hertz), which enables long detection ranges ${ }^{8,9}$.

Research on LFAS began in 1981 and a statement on its environmental impact was formally initiated in July 1996 by the US navy. The adverse effects of low-frequency sound on whales are poorly studied ${ }^{10}$, but many specialists warn that at high levels, as occurs with LFAS, they could be dramatic.

The proximity of military manoeuvres has been suspected of causing three previous atypical mass strandings of Cuvier's beaked whales, spread over wide areas of the Canary Islands ${ }^{6,11}$. On most of the extremely rare occasions that mass strandings are seen in this species, they show characteristics unlike those that occur with other whales. This suggests that the cause has a large synchronous spatial extent and a sudden onset. Such characteristics are shown by sound in the ocean. Also, deep-diving whales seem to be especially affected by low-frequency sounds, even at quite low received levels ${ }^{12,13}$.

We know that LFAS was used in the Kyparissiakos Gulf. We also know that no other LFAS tests or mass strandings have occurred in the Greek Ionian Sea since 1981. Taking the past 16.5-year period into account, the probability of a mass stranding occurring for other reasons during the period of the LFAS tests is less than $0.07 \%$.

Although pure coincidence cannot be excluded, it seems improbable that the two events were independent. Little is known about whales' reactions to LFAS; to obtain definitive answers, more information needs to be gathered. But unfortunately, most of the data about the use of LFAS are subject to military secrecy.

\section{A. Frantzis}

Zoological Laboratory, Department of Biology,

University of Athens, 15784 Athens, Greece

e-mail:afratzis@atlas.uoa.gr

1. Geraci, J. R. \& Lounsbury, V. J. Marine Mammals Ashore. A Field Guide for Strandings (Texas A\&M Sea Grant Publication, Galveston, Texas, 1993).

2. Heyning, J. E. in Handbook of Marine Mammals Vol. 4 (eds Ridgeway, S. H., Harrisson, R. J.) 289-308 (Academic Press, London, 1989)

3. Erdman, D. S., Harms, J. \& Flores, M. M. Cetology 17, 1-14 (1973).

4. Robinson, G., Koster, F. \& Villa, J. Noticias de Galapagos 38, 16-17 (1983).

5. Miyazaki, N. IBI Reports 1, 21-25 (International Marine Biological Research Institute, 1989)

6. Simmonds, M. P. \& Lopez-Jurado, L. F. Nature 337, 448 (1991).

7. Tortonese, E. Natura 54, 120-122 (1963).

8. Endeavour and Achievement (NATO-SACLANT Undersea Research Centre, La Spezia, Italy, 1993).

9. Saclantcen Newsletter 4 (NATO-SACLANT Undersea Research Centre, La Spezia, Italy, 1996-97).

10. Richardson, W. J. \& Würsig, B. Mar. Fresh. Behav. Physiol. 29, 183-209 (1997).

11. Vonk, R. \& Martin, V. European Research on Cetaceans 3, 73-77 (1989).

12. Watkins, W. A., Moore, K.E. \& Tyack, P. Cetology 49, 1-15 (1985). 13. Bowles, A.E. et al. J. Acoust. Soc. Am. 96, 2469-2484 (1994).

\section{Electron pairs shed light} on frustrated percolation

Cahn, in his News and Views article 1 , wondered why an arsenic-boron pair is best suited to 'stuff' a double vacancy in the crystal lattice in preference to a pair of boron atoms or arsenic atoms. The answer can be found if to describe bonding Linnett's model $^{2}$ for the covalent chemical bond is used. This is a generalization of the electronpair idea which incorporates the Pauli and
Ruedenberg principles and accounts well for molecular structures without resonance or configuration interaction.

Homogeneous dimers of either boron (B) or arsenic (As) in a brass matrix should not be more stable than monomers or homogeneous polymers, and their concentration should be low. Such polymers exist only in the less electronegative metals, so are not expected in zinc, copper or brass.

On the other hand, once boron arsenide (BAs) is formed in a metal, it is unlikely to grow by trapping free $\mathrm{B}$ and As atoms alternately - a concept that can be derived from its Linnett configuration. This way of describing compounds shows that the BAs molecule has three bonds, a pair of nonbonding electrons on the As and an empty site on the B atom. Therefore the molecule still has room to accept charge from the metal matrix. A more complete electron occupation then impedes further growth of the dimer. B and As oligomers exist in metal matrices but the BAs network does not - it exists only in the free cubic BAs solid. The BAs molecule should be stable in a metal matrix and it fits into the zinc double vacancy (divacancy) which has the right size. 
Alternative models are worth considering if they suggest new experiments ${ }^{3}$; this suggests several. First, it should be possible to replace As by $\mathrm{P}$ (and perhaps even $\mathrm{N}$ ) without a diminished anti-corrosive effect in brass. Second, other non-metal pairs as well as $\mathrm{B} /$ pnictide, such as $\mathrm{C}$ (or $\mathrm{Si}$ ) with $\mathrm{Si}$ (or $\mathrm{O})$, might behave similarly. Third, the solubility of B and As (or P) in brass may depend on each other's concentration and on the divacancy concentration. Novel quaternary intermetallic compounds of B and As might even be found. Finally, the trick should not work in alloys of metals below group 10 which corrode with a divacancy mechanism if formation of metal boride or arsenide phases competes.

\section{P. J. van der Put}

Laboratory of Inorganic Chemistry, Delft University of Technology, 2628 BL Delft, The Netherlands

e-mail:p.j.j.m.vanderput@stm.tudelft.nl

1. Cahn, R. W. Nature 389, 121 (1997).

2. Linnett, J. W. The Electronic Structure of Molecules. A New Approach (Methuen, London, 1964).

3. Oreskes, N., Shrader-Frechette, K. \& Belitz, K. Science 263, 641 (1994).

\section{Synthetic ligands point to cell surface strategies}

Protein shedding, the proteolytic release of a cell surface protein, can serve a regulatory role by liberating soluble molecules into circulation while decreasing their concentration on the cell surface ${ }^{1}$. We have created a new class of multivalent ligands, 'neoglycopolymers', which are designed to promote the proteolytic cleavage of a cell adhesion molecule involved in the inflammatory response, L-selectin ${ }^{2}$. These synthetic ligands induce the release of the extracellular portion of L-selectin by appropriating an endogenous protease; such activities suggest new strategies to generate anti-inflammatory agents and regulate the cell surface.

L-selectin mediates the process of leukocyte rolling ${ }^{3}$, an initial step in the inflammatory response, by recognizing carbohydrate epitopes that are present on endothelial cells. L-selectin is constitutively present on the surface of most leukocytes, but a soluble form is also found in circulation.

The L-selectin ligands that occur physiologically, such as GlyCAM-1 (ref. 4), are mucin-like proteins which contain clusters of $O$-linked saccharide chains. Such chains could engage L-selectin in multivalent binding at the cell surface. We hypothesized that the clustering of L-selectin, as a consequence of ligand binding, leads to the proteolytic release of its soluble form from the cell ${ }^{5}$.

So we synthesized molecules that, like mucins, present multiple copies of saccharide epitopes on an extended backbone.
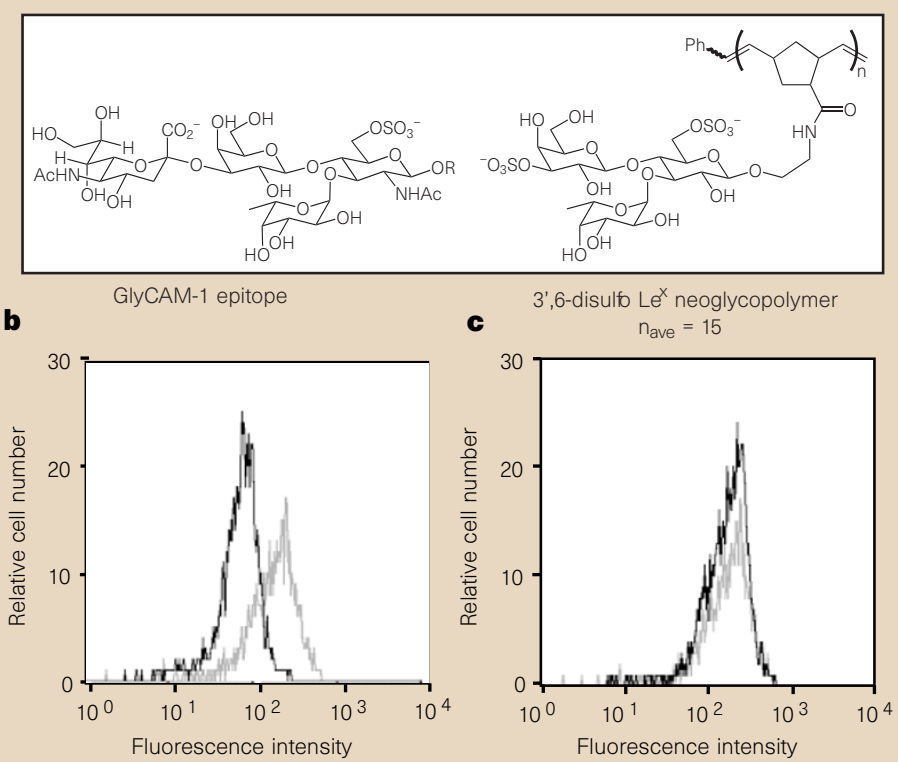

d

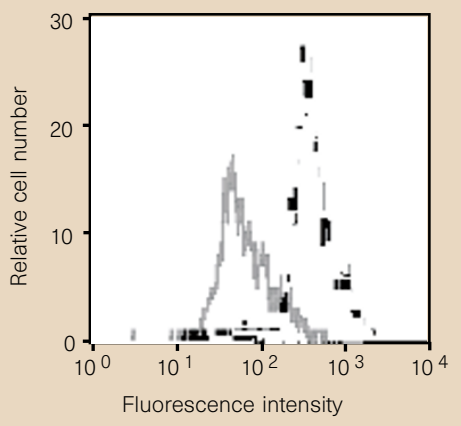

e

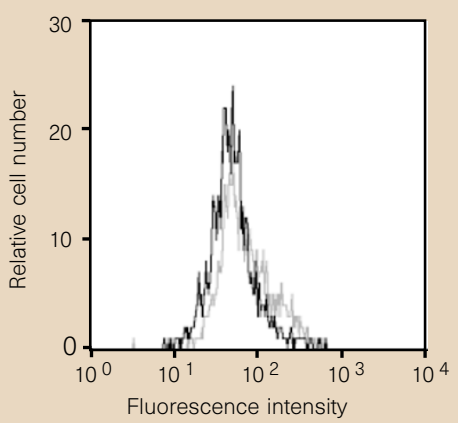

Figure 1 Effects of neoglycopolymer on human neutrophils. a, Chemical structures of an L-selectin binding epitope on GlyCAM-1 (Ac = acetyl) and the 3',6-disulpho Lex neoglycopolymer. b, Histogram overlay of L-selectin expression by untreated cells (grey) and cells treated with the 3',6-disulpho Le ${ }^{x}$ neoglycopolymer (267 $\mu \mathrm{M}$ or $4 \mathrm{mM}$ on a per saccharide basis; black). c, Histogram overlay of L-selectin expression by untreated cells (grey) and cells treated with the monomeric ligand 3',6-disulpho Le (Glc)- $\beta$-OPr (4 mM) (black). d. Histogram overlay of Mac-1 expression by untreated cells (grey) and cells treated with 10 nM PMA (black). e, Histogram overlay of Mac-1 expression by untreated cells (grey) and cells treated with 3',6-disulpho Lex neoglycopolymer (267 $\mu \mathrm{M}$ or $4 \mathrm{mM}$ on a per saccharide basis; black). Histogram depictions are representative of at least three experiments monitored by flow cytometry using a fluorescein isothiocyanate-conjugated anti-L-selectin antibody or a phycoerythrin-conjugated anti-Mac-1 antibody.

Such ligands might cluster L-selectin by mimicking either the mucins themselves or the multivalent display of mucin epitopes at the cell surface.

The L-selectin recognition element was based on the disulphated trisaccharide 3',6disulpho Lewis $\mathrm{x}\left(\mathrm{Le}^{\mathrm{x}}\right)$, an analogue of the GlyCAM-1 capping group 6-sulpho sialyl $\mathrm{Le}^{\mathrm{x} 4}$ (Fig. 1a). To assemble the recognition elements into a multivalent saccharide array $^{6}$, we used ruthenium carbenecatalyzed ring-opening metathesis polymerization (ROMP) ${ }^{7}$, a technique that tolerates multiple unprotected functionalities and can produce polymers of consistent and controllable lengths. We produced synthetic ligands composed of about 15 monomer units, each substituted with the recognition epitope 3',6-disulpho Le ${ }^{\mathrm{x}}$ (Fig. 1a) ${ }^{8}$.
When we treated human neutrophils with these neoglycopolymers, L-selectin was lost from the cell surface in a dosedependent manner (Fig. 1b). Soluble Lselectin was detected in the supernatant of treated cells; therefore the decrease on the cell surface was due to shedding.

In contrast, the monovalent ligand 3',6disulpho $\mathrm{Le}^{\mathrm{x}}(\mathrm{Glc})-\beta$-OPr did not cause Lselectin release (Fig. 1c). And a galactose-substituted oligomer, which does not bind L-selectin, had no effect.

Cellular activators, such as phorbol esters and chemotactic peptides, also induce the shedding of L-selectin; at the same time they dramatically increase the surface concentration of the $\beta 2$-integrin $\mathrm{Mac}-1$ (CD11b/CD18) (Fig. 1d), a protein involved in the next step of leukocyte 